\title{
Dynamic Safety Assessment in Nonlinear Hydropower Generation Systems
}

\author{
Shuang Li $\mathbb{D},{ }^{1}$ Yong Yang $\mathbb{D}{ }^{2}$ and Qing Xia $\mathbb{D}^{1}$ \\ ${ }^{1}$ School of Management, China University of Mining and Technology, Xuzhou, China \\ ${ }^{2}$ School of Computer Science and Technology, China University of Mining and Technology, Xuzhou, China \\ Correspondence should be addressed to Yong Yang; yyang@cumt.edu.cn
}

Received 9 December 2017; Revised 28 January 2018; Accepted 5 March 2018; Published 22 April 2018

Academic Editor: Diyi Chen

Copyright (c) 2018 Shuang Li et al. This is an open access article distributed under the Creative Commons Attribution License, which permits unrestricted use, distribution, and reproduction in any medium, provided the original work is properly cited.

\begin{abstract}
This paper focuses on the stability problems in a hydropower station. To enable this study, we consider a nonlinear hydropower generation system for the load rejection transient process based on an existing hydropower station. Herein we identify four critical variables of the generation system. Then, we carry out the dynamic safety assessment based on the Fisher discriminant method. The dynamic safety level of the system is determined, and the evolution behavior in the transient process is also performed. The result demonstrates that the hydropower generation system in this study case can operate safely, which is in a good agreement with the corresponding theory and actual engineering. Thus, the framework of dynamic safety assessment aiming at transient processes will not only provide the guidance for safe operation, but also supply the design standard for hydropower stations.
\end{abstract}

\section{Introduction}

Safety problems in hydropower stations generally cause power supply failures, economic loss of plants, and injury of workers $[1,2]$. Hydropower generation system (HGS) coupling with hydraulic-mechanical-electrical-magnetic nonlinear structures acts as a core part of a hydropower station, which is connected with the stability of the station [3-6]. Many safety accidents of the HGS occurred in the last thirty years all over the world [7-9]. For example, seventy-five persons lost their lives because of the damage of HGS in Sayano-Shushenskaya hydropower station (Russia) in 2009 [10]. An explosion accident caused by the rotor unbalance of HGS occurred in Huizhou hydropower station (China) in 2008, which resulted in enormous economic loss [11]. Therefore, it is important to assess the safety level in HGS to improve the stability of hydropower stations.

There are two operation types for the HGS including the small variation and large variation transient process. Generally, the large variation transient processes (i.e., load rejection, load increase/decrease, start-up, and shut-down) often result in unsteady operating conditions of the HGS, which may lead to the safety problems in the hydropower station. For example, the turbine flow and torque rapidly decrease during the load rejection transient process, which results in the fact that the system easily loses its control ability when system variables strongly change. Thus, we should pay more attention to the safety study of the HGS in the transient process, especially in the large variation.

Safety assessment has been extensively studied in many fields and has also obtained significant outcomes [12-15]. Conversely, the safety assessment in hydropower stations is still in the development stage. At present, this study mainly concentrates on the safety topics of flood disasters [16], sewage discharge [17], hydraulic accidents [18], and the safety of water gate [19]. For example, Ettles et al. calculated the safety margin for hydrogenerator thrust bearings [20]. Joannette studied the safety problem of the dam flood [21]. Yan et al. investigated the safety operation of the large hydroelectric generator unit [22]. Liu et al. used the fault monitoring and diagnosis system to study the dam safety [23]. However, the existing studies have not involved the safety study of HGS, which is therefore a great challenge due to its complex nonlinearity.

In light of the above consideration, this paper aims to assess the dynamic safety levels of the nonlinear HGS using 
the Fisher discriminant method. From the literature [24], Fisher discriminant method has the ability to identify the data with different attribute features by finding the optimal classification plane. That is, Fisher discriminant method can assess the safety levels of the system by successfully realizing the dimensionality reduction of the multidimension sample space. To date, Fisher discriminant method is widely used in many fields due to its advantage of efficient classification, as mentioned in literatures [24-26].

We have three innovations to make our paper attractive compared with the existing papers such as [27, 28]. First, few existing literatures have been proved successfully in applying the dynamic safety assessment to HGSs, especially in large fluctuation transient processes. To overcome this limitation, we focus on presenting a new framework for the dynamic safety assessment of transient HGSs by introducing the Fisher discriminant method. Second, we consider a nonlinear complex HGS that includes some typical nonlinear loops such as the elastic water hammer, the nonlinearity of generator rotor, and the self-excited oscillation. Based on this, four critical system variables are extracted to enable the dynamic safety assessment. Finally, a dynamic safety assessment analysis aiming at the presented HGS for the load rejection transient process is carried out. We show the details of the safety evolution of the HGS during the transient process. From the perspective of statistical theory, the probabilities of dynamic safety levels of the HGS for the transient process are extensively investigated.

The rest of the paper is organized as follows. In Section 2, we review a nonlinear HGS for the load rejection transient process based on an existing hydropower station. In Section 3, we introduce the research method and review the powerful statistical approach called Fisher discriminant method. Section 4 carries out the dynamic safety assessment of the above HGS. Section 5 presents a comparative analysis. Conclusions in Section 6 close this paper.

\section{Nonlinear Hydropower Generation System}

Hydropower generation system (HGS) as an important part in hydropower station is directly related to the safety of power grid. HGSs are complex system integrated with multiple nonlinear structures. In general, a complete nonlinear HGS is composed of seven typical structures, that is, reservoirs, penstock systems, governors, generators, hydraulic turbine, surge tanks, and draft tubes, which can be shown in Figure 1.

In fact there are two operating types for HGSs in the practical hydropower station, which are the small and large variation transient processes [29]. The small variation transient process refers to the load disturbance less than $10 \%$; otherwise we define it as the large variation transient process [30]. Five typical large variation transients including the power on/off, the load rejection, and the sudden decrease/increase of load have attracted more attention of the researchers all over the world for their ubiquity in hydropower stations. Unexpected accidents caused by the large variation transient will result in serious consequences such as injury and economic loss.

The load rejection transient herein is a study case to further investigate the safety of HGS. As is known to all, the

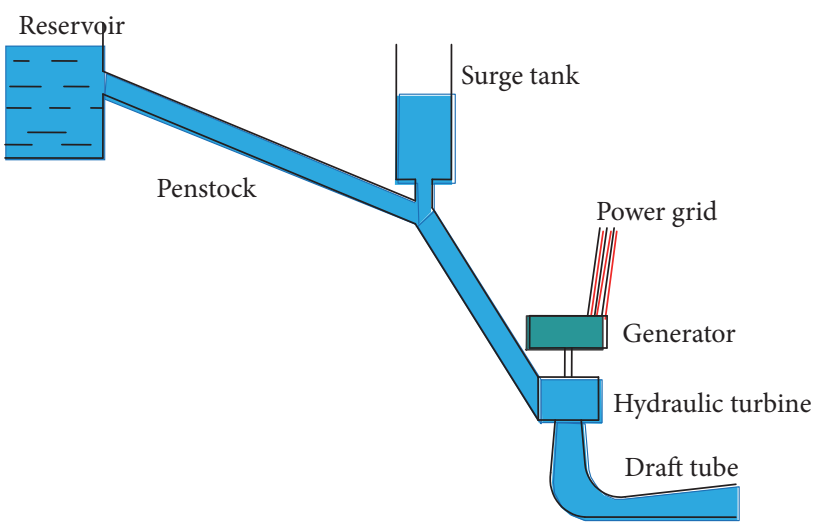

FIGURE 1: Diagram of an elementary hydropower generation system.

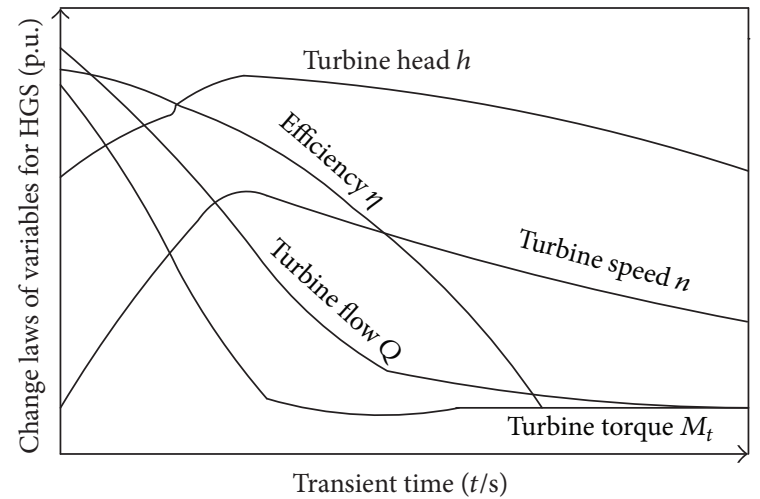

FIGURE 2: Schematic diagram of the change laws of variables in the nonlinear HGS during the load rejection transient process.

variable of system fluctuates dramatically because the HGS is a high coupled nonlinear system in the load rejection transient. For example, during this transient process, the flow and the torque of hydraulic turbine decrease rapidly with the close of guide vane. Meanwhile, the speed of hydraulic turbine first increases and then decreases. Figure 2 is the schematic diagram of the change laws of variables in HGS.

In this paper, we study the performance of HGS based on an existing hydropower station. Therefore, the closing law of guide vane for the load rejection transient is shown in Figure 3 [31]. It uses two-stage closure mode, and its total transient time is 30 seconds.

Based on the above consideration, we adopt the experimental data and HGS model presented in [31] to obtain the predictive data of the dynamic safety assessment. The dynamic characteristic of the HGS is described by the motion equation and continuity equation shown as

$$
\begin{gathered}
g \frac{\partial H}{\partial x}+\frac{\partial V}{\partial t}+V \frac{\partial V}{\partial x}+\frac{f V|V|}{2 D}=0 \\
\frac{\partial H}{\partial t}+V \frac{\partial H}{\partial x}-V \sin \alpha+\frac{a^{2}}{g} \frac{\partial v}{\partial x}=0
\end{gathered}
$$

where $H, V, x, D, a, f, g$, and $\alpha$ are the piezometric head of penstock, the flow velocity, the displacement along penstock direction, the diameter of penstock, the water hammer wave speed, the Darcy-Weisbach resistance coefficient, the 


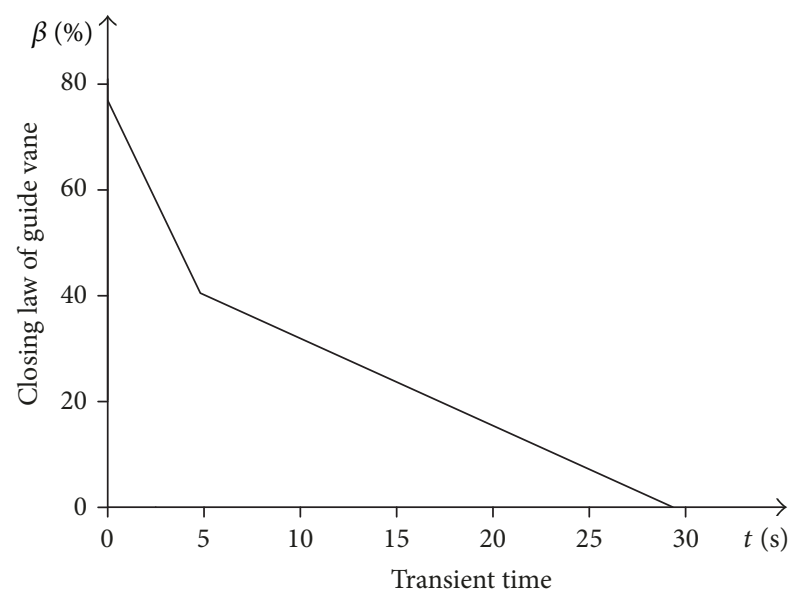

Figure 3: Closing law of an existing HGS in the load rejection transient process.

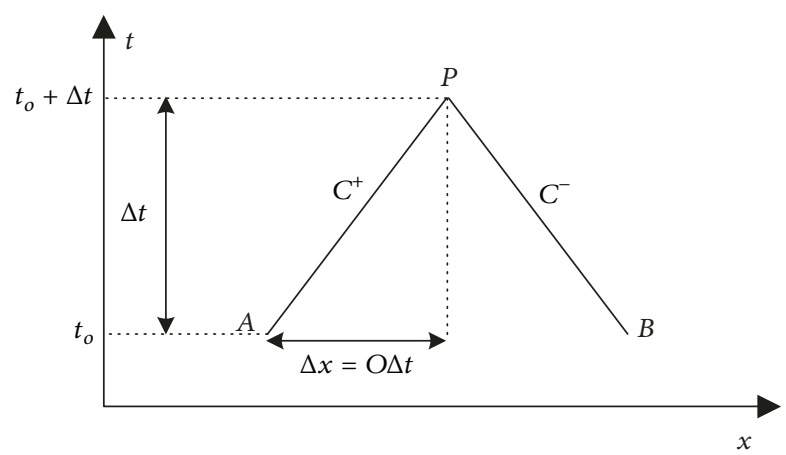

Figure 4: The working mechanism of the characteristic line. $A$ and $B$ represent the sectional areas in the upstream pipe and downstream pipe, respectively. When the diameter of pipe keeps unchanged, the sectional area $A$ equals $B$.

gravitational acceleration, and the angle between penstock and horizontal direction, respectively.

Based on the working mechanism of the characteristic line shown in Figure 4, (1) can be converted to the positive and negative characteristic equation, that is,

$$
\begin{aligned}
& C+: Q_{p}=C_{p}-C_{a} H_{p} \\
& C-: Q_{p}=C_{n}-C_{a} H_{p},
\end{aligned}
$$

where the subscript $p$ denotes the value at the arbitrary time t. $H_{p}$ and $Q_{p}$ are, respectively, the pressure and flow of the pipe, and they can be described as in (3). $C_{p}, C_{n}$, and $C_{a}$ are expressed as in (4).

$$
\begin{aligned}
Q_{p} & =0.5\left(C_{p}+C_{n}\right) \\
H_{p i} & =\frac{\left(C_{p i}-\sum_{j=1}^{x} C_{n j}\right)}{\left(C_{a i}+\sum_{j=1}^{x} C_{a j}\right)}, \\
C_{p} & =Q_{A}+\frac{g A}{a} H_{A}-\frac{f \Delta t}{2 D A} Q_{A}\left|Q_{A}\right| \\
C_{n} & =Q_{B}-\frac{g A}{a} H_{B}-\frac{f \Delta t}{2 D A} Q_{B}\left|Q_{B}\right| \\
C_{a} & =\frac{g A}{a} .
\end{aligned}
$$

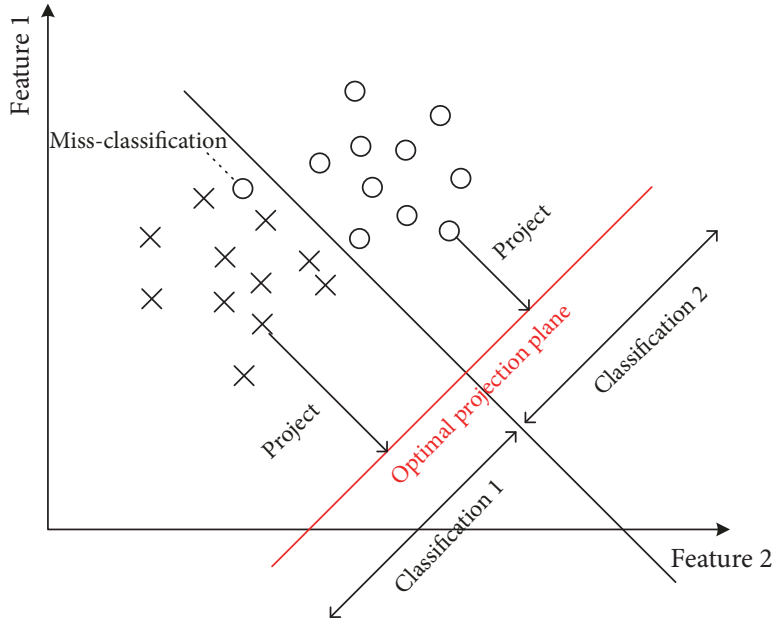

$\times$ Data 1

Data 2

FIgURE 5: Schematic diagram of Fisher discriminant method.

Here, the pressure $H_{p}$ and flow $Q_{p}$ in (2) are universal expressions, which can be used to calculate the pressure and flow of the hydraulic turbine, the draft tube, the spiral case, and the surge tank as the values of characteristic parameters change. These characteristic parameters include the sectional areas $A$ and $B$, the flow velocity $V$, the water hammer wave speed $a$, and the angle between penstock and horizontal direction $\alpha$. Furthermore, based on the characteristic curve of flow and speed of hydraulic turbine presented in [31], we also obtain the change law of the speed of hydraulic turbine.

\section{Methodology}

In this study, a universal Fisher discriminant method [24$26]$ is used to handle and to analyze the predictive HGS with multisample for the load rejection transient process. The basic idea of Fisher discriminant method is based on the projection theory, which successfully realizes the dimensionality reduction of the multidimension sample space and finally finds the optimal classification plane. We use the training data/samples with multiple variables that have been already sure of their safety levels to analyze the predictive data/samples. That is, we project the training data/samples onto the optimal projection plane that gets as few miss-classifications as possible. The different classification intervals are also determined in the optimal projection plane, as shown in Figure 5. Similarly, we project the predictive data/samples onto the optimal projection plane and then observe its classification interval. In doing so, the safety level of predictive data/samples will be obtained. In this paper, hence, the Fisher discriminant method is used to achieve the dynamic safety assessment of the HGS in the load rejection transient process.

The primary formula of Fisher discriminant method can be described as follows: we assume that there is a linear discriminant function $\mathbf{u}^{\prime} \mathbf{X}$ for the training group $H_{i}(i=$ $1,2, \ldots, k)$. Its mean matrix and covariance matrix are, respectively, $\boldsymbol{\mu}_{i}$ and $\boldsymbol{\Sigma}_{i}$, which can be expressed as 


$$
\begin{aligned}
& E\left(\mathbf{u}^{\prime} \mathbf{X}\right)=\mathbf{u}^{\prime} E\left(\mathbf{X} \mid H_{i}\right)=\mathbf{u}^{\prime} \boldsymbol{\mu}_{i} \\
& D\left(\mathbf{u}^{\prime} \mathbf{X}\right)=\mathbf{u}^{\prime} D\left(\mathbf{X} \mid H_{i}\right) \mathbf{u}=\mathbf{u}^{\prime} \Sigma_{i} \mathbf{u}, \\
& \qquad i=1,2, \ldots, k .
\end{aligned}
$$

The objective function $\Phi(\mathbf{u})$ with respect to the linear discriminant coefficient $\mathbf{u}$ is expressed as

$$
\Phi(\mathbf{u})=\frac{\sum_{i=1}^{k}\left(\mathbf{u}^{\prime} \boldsymbol{\mu}_{i}-\mathbf{u}^{\prime} \overline{\boldsymbol{\mu}}\right)^{2}}{\sum_{i=1}^{k} \mathbf{u}^{\prime} \Sigma_{i} \boldsymbol{\mu}}
$$

where $\overline{\boldsymbol{\mu}}=(1 / k) \sum_{i=1}^{k} \boldsymbol{\mu}_{i}$ and $\mathbf{E}=\sum_{i=1}^{k} \Sigma_{i}$.

Meanwhile, the linear discriminant function $\mathbf{u}^{\prime} \mathbf{X}$ should meet the following discriminant law:

$$
\left|\mathbf{u}^{\prime} \mathbf{X}-\mathbf{u}^{\prime} \boldsymbol{\mu}_{j}\right|=\min _{1 \leq i \leq k}\left|\mathbf{u}^{\prime} \mathbf{X}-\mathbf{u}^{\prime} \boldsymbol{\mu}_{i}\right| \text {. }
$$

To obtain the final linear discriminant function, we make the objective function $\Phi(\mathbf{u})$ reach to its maximal value. That is, the objective function $\Phi(\mathbf{u})$ satisfies

$$
\begin{aligned}
& \mathbf{u}^{\prime} \frac{\partial \phi}{\partial \mathbf{u}}=2 \lambda\left(1-\mathbf{u}^{\prime} \mathbf{E u}\right)=0 \\
& \mathbf{u}^{\prime} \frac{\partial \phi}{\partial \lambda}=\mathbf{u}^{\prime}\left(\mathbf{u}^{\prime} \mathbf{E} \mathbf{u}-1\right)=0 .
\end{aligned}
$$

By solving (8), we can obtain the final linear discriminant function; that is,

$$
U(\mathbf{X})=u_{1} X_{1}+u_{2} X_{2}+\cdots+u_{p} X_{p}=\mathbf{u}^{\prime} \mathbf{X} .
$$

To conclude, the overall methodology of this paper is performed in Figure 6, and the procedure of dynamic safety assessment of the HGS in the transient process is described as below:

(1) Preparatory work: to enable the dynamic safety assessment, we should analyze the accident of the HGS and also obtain the training and predictive HGS data.

(2) Use the Fisher discriminant method to judge the safety level of the predictive data at the transient time $i$.

(3) Update the safety level of the HGS by repeating step (2).

(4) Understand the safety evolution process and obtain the dynamic safety level of the HGS in the transient process.

\section{Dynamic Safety Assessment of HGSs}

4.1. Basic Information. In this paper, the safety assessment of a nonlinear HGS is carried out on the basis of an existing hydropower station, and its basic information including the head level and hydraulic turbine is listed in Tables 1 and 2 [31]. In addition to this, the research condition of the HGS is the load rejection transient process. More specifically, the upstream reservoir and tailrace outlet are in the check flood level. In this case, the HGS discards its full load, and the transient time is 30 seconds.

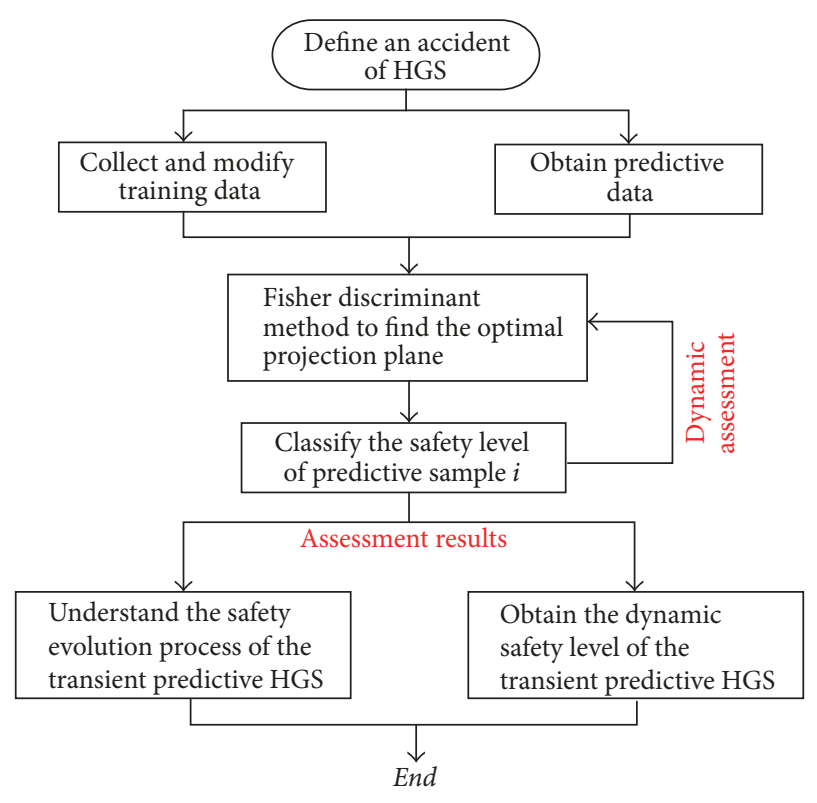

Figure 6: Overall methodology of this work.

TABLE 1: Head level information of an existing HGS.

\begin{tabular}{lc}
\hline Parameters of the HGS & Values \\
\hline Normal water level of upstream reservoir & $1300 \mathrm{~m}$ \\
Designed flood level of upstream reservoir & $1300.53 \mathrm{~m}$ \\
Check flood level of upstream reservoir & $1301.56 \mathrm{~m}$ \\
Dead water level of upstream reservoir & $1280 \mathrm{~m}$ \\
Designed flood level in tailrace outlet & $1152.85 \mathrm{~m}$ \\
Check flood level in tailrace outlet & $1155.52 \mathrm{~m}$ \\
\hline
\end{tabular}

TABLE 2: Hydraulic turbine information of an existing HGS.

\begin{tabular}{lc}
\hline System parameters & Values/information \\
\hline Type of hydraulic turbine & HLFI034-LJ-176 \\
Nominal head & $129 \mathrm{~m}$ \\
Nominal speed & $428.6 \mathrm{r} / \mathrm{min}$ \\
Installation height & $1147.5 \mathrm{~m}$ \\
Maximum head & $149 \mathrm{~m}$ \\
Minimum head & $119 \mathrm{~m}$ \\
Nominal power & $20.62 \mathrm{Mw}$ \\
Moment of inertia & $320 \mathrm{t} \cdot \mathrm{m}^{2}$ \\
\hline
\end{tabular}

4.2. Dynamic Safety Analysis. To enable this dynamic safety assessment, the training date and predictive data of the HGS for the load rejection transient process are, respectively, performed in Table $3[32,33]$ and Figure 7 [31]. Herein four critical system variables expressed by the relative values; that is, the speed of hydraulic turbine $n$, the pressure of spiral case $p_{1}$, the pressure of draft tube $p_{2}$, and the pressure of surge tank $p_{3}$ are extracted to express the characteristic of the HGS. Twenty-one predictive data sets of HGS are selected along with the transient point $t$. The safety levels of data comprised of four grades (i.e., Safety, Tolerable, Unstable, and Risk) are from the modified expert experience since there is 
TABLE 3: Training data of the HGS in the load rejection transient process.

\begin{tabular}{|c|c|c|c|c|}
\hline \multicolumn{5}{|c|}{ Relative values of variables in HGS (p.u.) } \\
\hline Speed of hydraulic turbine $n$ & Pressure of spiral case $p_{1}$ & Pressure of draft tube $p_{2}$ & Pressure of surge tank $p_{3}$ & Safety level \\
\hline 1 & 1.0547 & 0.94 & 0.9948 & Safety \\
\hline 0.2971 & 0.9867 & 0.8389 & 0.9995 & Safety \\
\hline 0.2121 & 0.9965 & 0.8052 & 0.9986 & Safety \\
\hline 0.149 & 0.9942 & 0.8354 & 0.9976 & Safety \\
\hline 0.1271 & 1.0017 & 0.9234 & 1.0005 & Safety \\
\hline 0.1065 & 1.0194 & 1.0009 & 1.0033 & Safety \\
\hline 0.1175 & 1.0397 & 0.9063 & 1.004 & Safety \\
\hline 0.1 & 1.0192 & 0.9 & 1.0046 & Safety \\
\hline 1.2282 & 1.075 & 0.9908 & 0.9995 & Tolerable \\
\hline 1.2913 & 1.1025 & 0.9637 & 1.0059 & Tolerable \\
\hline 1.3543 & 1.143 & 0.9063 & 1.0113 & Tolerable \\
\hline 1.2282 & 1.317 & 1.2917 & 0.9998 & Tolerable \\
\hline 1.1651 & 1.2843 & 1.3692 & 1.004 & Tolerable \\
\hline 1.1116 & 1.2516 & 1.4265 & 1.0084 & Tolerable \\
\hline 0.9951 & 1.2111 & 1.43 & 1.0097 & Tolerable \\
\hline 0.921 & 1.1731 & 1.3827 & 1.0062 & Tolerable \\
\hline 0.8264 & 1.1329 & 1.3284 & 1.0033 & Tolerable \\
\hline 0.7524 & 1.1178 & 1.2238 & 0.9989 & Tolerable \\
\hline 0.6783 & 1.0949 & 1.1226 & 0.9967 & Tolerable \\
\hline 0.5713 & 1.09 & 1.0784 & 1.0024 & Tolerable \\
\hline 0.4767 & 1.0773 & 1.0075 & 1.0062 & Tolerable \\
\hline 0.4136 & 1.0472 & 0.9365 & 1.0052 & Tolerable \\
\hline 0.3286 & 1.0092 & 0.9063 & 1.0008 & Tolerable \\
\hline 1.4188 & 1.1708 & 0.8389 & 1.0141 & Unstable \\
\hline 1.4394 & 1.2464 & 1.021 & 1.0027 & Unstable \\
\hline 1.4078 & 1.287 & 1.0854 & 0.9963 & Unstable \\
\hline 1.3653 & 1.317 & 1.1599 & 0.9935 & Unstable \\
\hline 1.3228 & 1.3625 & 1.2273 & 0.9957 & Unstable \\
\hline 1.4503 & 1.1859 & 0.8288 & 1.0126 & Risk \\
\hline 1.4928 & 1.1908 & 0.8052 & 1.0132 & Risk \\
\hline 1.5024 & 1.1784 & 0.8017 & 1.0139 & Risk \\
\hline 1.4709 & 1.1656 & 0.8082 & 1.0122 & Risk \\
\hline 1.4928 & 1.1607 & 0.8862 & 1.0091 & Risk \\
\hline 1.4613 & 1.2062 & 0.9873 & 1.0065 & Risk \\
\hline
\end{tabular}

no unified standard for the safety assessment of HGSs. The property of four safety levels of the HGS can be described as follows: (a) Safety level means that the HGS works normally. (b) Tolerable level refers to the operation of HGSs with slight vibrations/fluctuations. (c) Unstable level refers to the operation of HGSs with strong vibrations/fluctuations, which should attract the attention of maintenance. (d) Risk level reveals that the HGS cannot work before the repair or replacement.

The training data of HGS in Table 3 is acquired based on the documented experiments and theoretical modification, which can be found in $[32,33]$. For the predictive data in Figure 7 , it shows the change law of four critical system variables in the load rejection transient process. The predictive data comes from the HGS model presented in the literature [31]. To simplify the calculation of this paper, we use the relative value of the studied variables. The relative value is defined as the ratio between actual value and nominal value.

Based on Table 3 and Figure 7, we use the Fisher discriminant method to analyze the training data in order to classify the safety level of predictive data of the above HGS in the load rejection transient process. The dynamic safety assessment results of the HGS, including the dynamic safety level and dynamic behavior evolution, are shown in Figure 8.

Figure 8 clearly shows the dynamic change of safety level for the nonlinear HGS with the transient time $t$. We find that a large fluctuation of the HGS is mainly concentrated in the transient time range $t(0,19)$. That is, during this time interval, the system experiences the Unstable and Tolerable levels. Conversely, the system is in a safety state as the transient time varies from $t=19$ to $t=30$. This implies that the HGS suffers a higher disturbance between the transient time $t=0$ and $t=19$ compared with the end stage of this transient process. In fact, it is tightly related to the sudden rejection of the system load, which results in the significant change of system variables. In addition, there are two notable points. The first is that the HGS is in a Tolerable level at the transient time $t=0$. It means that the fluctuation has taken place for the HGS with the discarding of load. The second is that the HGS does not undergo the Risk level, which means that the studied nonlinear system can realize the efficient self-regulation and resists a great change of power grid.

Moreover, we report the dynamic statistical ratios of the HGS for the four safety levels, as shown in the bar chart of 


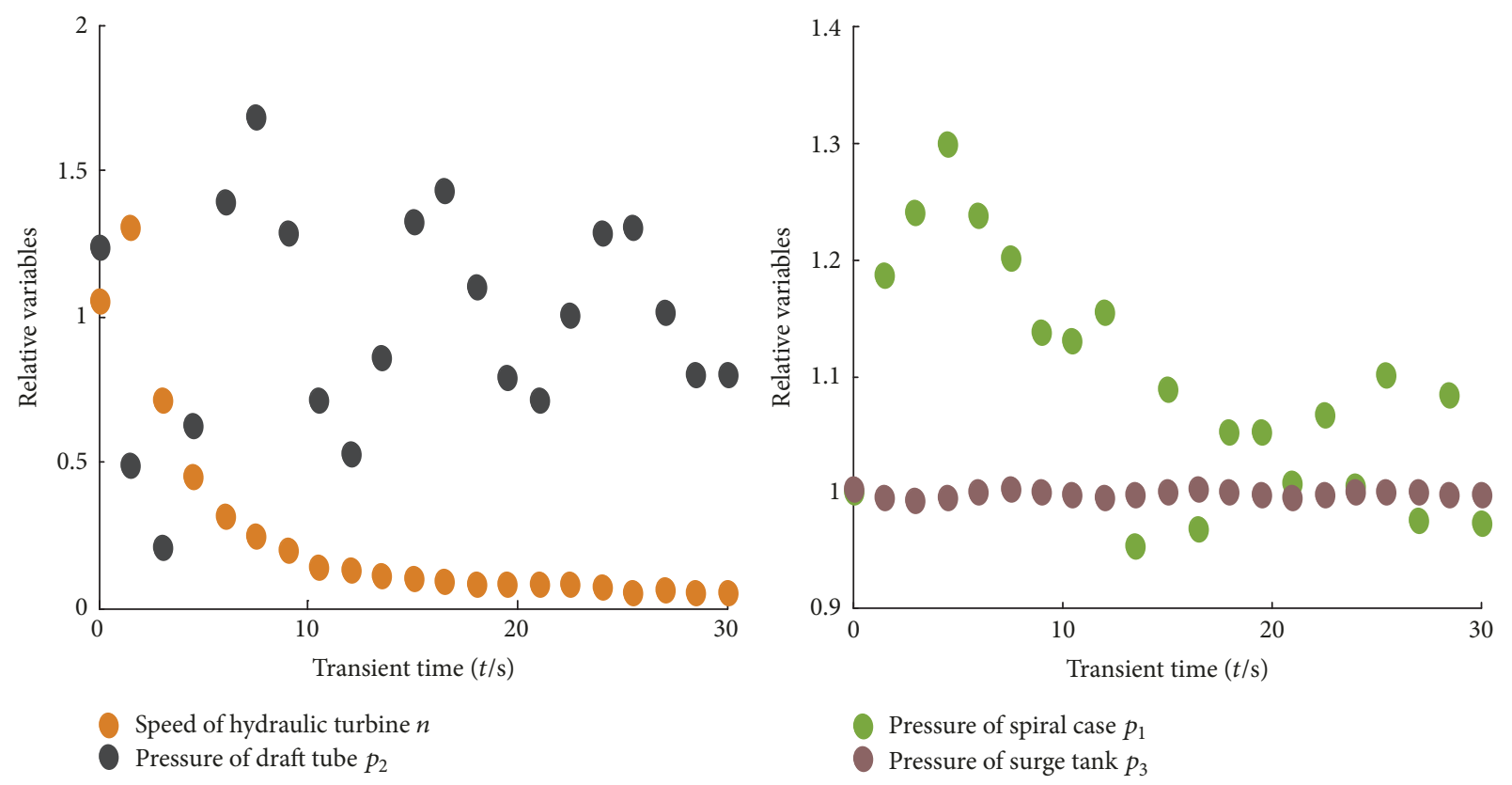

FIGURE 7: Predictive data of a nonlinear HGS for the load rejection transient process.
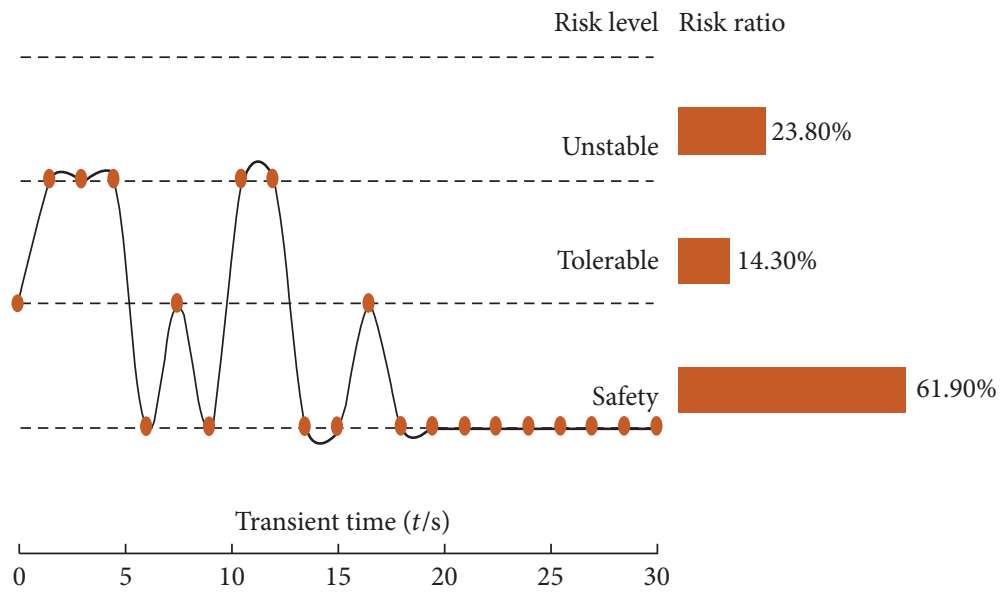

FIGURE 8: Dynamic safety assessment results of the predictive HGS during the load rejection transient process.

Figure 8. It is demonstrated that the probabilities of Risk, Unstable, Tolerable, and Safety are, respectively, 0, 23.8\%, $14.3 \%$, and $61.9 \%$. In other words, the HGS keeps stable for more than half the transient time; meanwhile, there is no risk. From the point of view of internal coupling mechanism, this research result reveals that the HGS can be effectively compatible with its hydraulic, mechanical, and electrical structures.

\section{Comparisons}

Based on the pipe water pressure testing of the studied HGS presented in [31], the measured maximum and minimum pressures in the penstock/draft pipe/surge tank meet the safety requirement of the hydropower station. This means that the studied HGS cannot suffer the failure in the load rejection transient process (i.e., the probability of Risk level is 0 ). Moreover, the testing result also reveals that the studied HGS operates normally for the bulk of transient time while it suffers the strong and slight fluctuations for the minor part of time. This is consistent with the probability assessment result referring to the Safety level $61.9 \%$ being more than the Tolerable level of $14.3 \%$ and Unstable level of $23.8 \%$. However, it is a challenge to estimate the probabilities of Tolerable level and Unstable level in the pipe water pressure testing. Thus, we can conclude that the dynamic safety assessment results of this study can generally reflect the safety of the studied HGS.

\section{Conclusions and Discussion}

In this paper, we have presented a dynamic framework of safety assessment of HGSs in transient processes. To achieve this, we consider a nonlinear HGS for the load rejection 
transient process from an existing hydropower station, and the critical system variables are extracted. Then, we have assessed the safety of the HGS using the Fisher discriminant method. The dynamic safety evolution process has been studied, and the safety level has also been determined during this transient process. The result demonstrates that the nonlinear HGS studied in this paper has a better stability because it is in the Safety and Tolerable levels about the probability of $76.2 \%$ during the load rejection transient. Meanwhile, there is no Risk level for this HGS. It also reveals that the HGS achieves the perfect performance of antidisturbance and the harmonious operation of its different parts. However, the Fisher discriminant method is a linear projection approach, which may not better reflect some uncertainties existing in the HGS. Therefore, future work will explore a more rigorous evaluation method to improve the reliability of the assessment result.

To date, not many studies pay attention to assessing the safety level of the HGS in large fluctuation transient processes. To overcome this limitation, this work presents a new framework for the dynamic safety assessment of transient HGSs. This not only provides the operation guidance of HGSs, but also gives the design standard for the safe operation of hydropower stations. Furthermore, although the proposed Fisher discriminant method can realize the dimensionality reduction of the multidimension variables for the transient HGS, some drawbacks may not be ignored. For instance, the linear discriminant function (as mentioned in (9)) is generally used to classify the predictive data, which may increase classifying errors. Thus future work will concentrate on the investigation of nonlinear discriminant functions.

\section{Nomenclature}

$\begin{array}{ll}A: & \text { Sectional area of the upstream pipe, } \mathrm{m}^{2} \\ a: & \text { Water hammer wave speed, } \mathrm{m} / \mathrm{s} \\ B: & \text { Sectional area of the downstream pipe, } \mathrm{m}^{2} \\ C^{+}: & \text {Positive characteristic line } \\ C^{-}: & \text {Negative characteristic line } \\ C_{p}, C_{n} \text { and } C_{a}: & \text { Intermediate variables } \\ D: & \text { Diameter of penstock, } \mathrm{m} \\ f: & \text { Darcy-Weisbach resistance coefficient } \\ h: & \text { Hydroturbine speed, rad/s } \\ H: & \text { Piezometric head of penstock, } \mathrm{m} \\ H_{p}: & \text { Pressure of the penstock } \\ g: & \text { Gravitational acceleration, } \mathrm{m} / \mathrm{s}^{2} \\ M_{t}: & \text { Mechanical torque of the hydroturbine, } \\ & \text { N.m } \\ n: & \text { Guide vane opening, rad } \\ \mathrm{Q}: & \text { Hydroturbine flow, } \mathrm{m}^{3} / \mathrm{s} \\ Q_{p}: & \text { Flow of the penstock } \\ t: & \text { Transient time, } \mathrm{s} \\ \mathbf{u}: & \text { Linear discriminant coefficient } \\ \mathbf{u}^{\prime} \mathbf{X}: & \text { Linear discriminant function } \\ V: & \text { Flow velocity, } \mathrm{m} / \mathrm{s} \\ x: & \text { Displacement along penstock direction, } \mathrm{m}\end{array}$

$\alpha: \quad$ Angle between penstock and horizontal direction, rad

$\beta: \quad \quad$ Guide vane opening, $\%$

$\eta: \quad$ Hydroturbine efficiency, \%

$\boldsymbol{\mu}: \quad$ Mean matrix

$\Phi(\mathbf{u}): \quad$ Objective function

$\Sigma: \quad$ Covariance matrix

Subscript $i$ : Number of training groups

Subscript $p$ : Value at the arbitrary time $t$.

\section{Conflicts of Interest}

The authors declare that they have no conflicts of interest.

\section{Acknowledgments}

This study was supported by the National Natural Science Foundation of China (71573256) and the National Key Research and Development Plan of China (2017YFC0804408).

\section{References}

[1] E. Shayesteh, M. Amelin, and L. Soder, "Multi-Station equivalents for Short-term hydropower scheduling," IEEE Transactions on Power Systems, vol. 31, no. 6, pp. 4616-4625, 2016.

[2] S. Das, I. Pan, and S. Das, "Fractional order fuzzy control of nuclear reactor power with thermal-hydraulic effects in the presence of random network induced delay and sensor noise having long range dependence," Energy Conversion and Management, vol. 68, pp. 200-218, 2013.

[3] S.-M. Lu and D.-J. Li, "Adaptive neural network control for nonlinear hydraulic servo-system with time-varying state constraints," Complexity, Art. ID 6893521, 11 pages, 2017.

[4] H. Li, D. Chen, H. Zhang, C. Wu, and X. Wang, "Hamiltonian analysis of a hydro-energy generation system in the transient of sudden load increasing," Applied Energy, vol. 185, pp. 244-253, 2017.

[5] N. Kishor, S. P. Singh, and A. S. Raghuvanshi, "Dynamic simulations of hydro turbine and its state estimation based LQ control," Energy Conversion and Management, vol. 47, no. 18-19, pp. 3119-3137, 2006.

[6] B. Hashtarkhani, M. P. Aghababa, and M. J. Khosrowjerdi, "Design of a robust nonlinear controller for a synchronous generator connected to an infinite bus," Complexity, vol. 21, no. 5, pp. 203-213, 2016.

[7] C. Zhou, Q. Jiang, W. Wei, Y. Chen, and G. Rong, "Safety monitoring and stability analysis of left bank high slope at Jinping-I hydropower station," Quarterly Journal of Engineering Geology and Hydrogeology, vol. 49, no. 4, pp. 308-321, 2016.

[8] L. Yang, W. Zhang, B. Yu, and L. Liu, "Safety evaluation of branch pipe in hydropower station using elastic modulus reduction method," Journal of Pressure Vessel Technology, Transactions of the ASME, vol. 134, no. 4, Article ID 041205, 2012.

[9] N. Dellinger, P. François, D. Lefebure, R. Mose, and P.-A. Garambois, "An experiment of a hydropower conversion system based on vortex-induced vibrations in a confined channel," Journal of Renewable Energy, vol. 115, pp. 54-63, 2018.

[10] V. E. Fortov, M. P. Fedorov, and V. V. Elistratov, "Scientific and technological problems of the hydropower industry after the accident at the Sayano-Shushenskaya hydropower plant," 
Herald of the Russian Academy of Sciences, vol. 81, no. 4, pp. 333340, 2011.

[11] K. Bian, J. Liu, M. Xiao, and Z. Liu, "Cause investigation and verification of lining cracking of bifurcation tunnel at Huizhou Pumped Storage Power Station," Tunnelling and Underground Space Technology, vol. 54, pp. 123-134, 2016.

[12] D. Huang, Y. Zhao, and Y. L. Chen, "Safety evaluation of a collapsed turbine wind on the buried pipeline," Engineering Failure Analysis, vol. 82, pp. 47-55, 2017.

[13] R. Rocchetta and E. Patelli, "Assessment of power grid vulnerabilities accounting for stochastic loads and model imprecision," International Journal of Electrical Power \& Energy Systems, vol. 98, pp. 219-232, 2018.

[14] A. M. Saedi, J. J. Thambirajah, and A. Pariatamby, "A HIRARC model for safety and risk evaluation at a hydroelectric power generation plant," Safety Science, vol. 70, pp. 308-315, 2014.

[15] J.-L. Zhou, B. Zhe-Hua, and Z.-Y. Sun, "Safety assessment of high-risk operations in hydroelectric-project based on accidents analysis, SEM, and ANP," Mathematical Problems in Engineering, vol. 2013, Article ID 530198, 2013.

[16] A. Schumann, "Flood Safety versus Remaining Risks - Options and Limitations of Probabilistic Concepts in Flood Management," Water Resources Management, vol. 31, no. 10, pp. 31313145, 2017.

[17] E. Nixdorf, Y. Sun, M. Lin, and O. Kolditz, "Development and application of a novel method for regional assessment of groundwater contamination risk in the Songhua River Basin," Science of the Total Environment, vol. 605-606, pp. 598-609, 2017.

[18] Z. Chen, P. M. Singh, and Y. Choi, "Suppression of unsteady swirl flow in the draft tube of a Francis hydro turbine model using J-Groove," Journal of Mechanical Science and Technology, vol. 31, no. 12, pp. 5813-5820, 2017.

[19] Y. Liang and W. Chen, "Reliability analysis for sluice gate anti-sliding stability using Lévy stable distributions," Signal Processing, vol. 107, pp. 425-432, 2015.

[20] C. M. Ettles, J. Seyler, and M. Bottenschein, "Calculation of a safety margin for hydrogenerator thrust bearings," Tribology Transactions, vol. 48, no. 4, pp. 450-456, 2005.

[21] J. Joannette, "Effects of risk on the determination of the dams flood safety at Hydro-Quebec," La Houille Blanche, no. 5, pp. 59-64, 2014.

[22] Z. G. Yan, T. Cui, L. J. Zhou, F. L. Zhi, and Z. W. Wang, "Study on safety operation for large hydroelectric generator unit," IOP Conference Series: Earth and Environmental Science, vol. 15, no. 2, p. 022022, 2012.

[23] H. Liu, C. Ren, Z. Zheng, Y. Liang, and X. Lu, "Study of a Gray Genetic BP Neural Network Model in Fault Monitoring and a Diagnosis System for Dam Safety," ISPRS International Journal of Geo-Information, vol. 7, no. 2, p. 4, 2018.

[24] W. Li, Y. Wang, Z. Xu, Y. Jiang, Z. Lu, and Q. Liao, "Weighted contourlet binary patterns and image-based fisher linear discriminant for face recognition," Neurocomputing, vol. 267, pp. 436-446, 2017.

[25] M. R. Galiaskarov, V. V. Kurkina, and L. A. Rusinov, “Online diagnostics of time-varying nonlinear chemical processes using moving window kernel principal component analysis and Fisher discriminant analysis," Journal of Chemometrics, vol. 31, no. 8, Article ID e2866, 2017.

[26] Z. Zhang, H. Zhang, Y. Wen, Y. Zhang, and X. Yuan, "Discriminative extraction of features from time series," Neurocomputing, vol. 275, pp. 2317-2328, 2018.
[27] B. Xu, D. Chen, H. Zhang, and R. Zhou, "Dynamic analysis and modeling of a novel fractional-order hydro-turbine-generator unit," Nonlinear Dynamics, vol. 81, no. 3, pp. 1263-1274, 2015.

[28] H. Li, D. Chen, B. Xu, S. Tolo, and E. Patelli, "Dynamic analysis of multi-unit hydropower systems in transient process," Nonlinear Dynamics, vol. 90, no. 1, pp. 535-548, 2017.

[29] B. Xu, F. Wang, D. Chen, and H. Zhang, "Hamiltonian modeling of multi-hydro-turbine governing systems with sharing common penstock and dynamic analyses under shock load," Energy Conversion and Management, vol. 108, pp. 478-487, 2016.

[30] N. Kishor, R. P. Saini, and S. P. Singh, "A review on hydropower plant models and control," Renewable \& Sustainable Energy Reviews, vol. 11, no. 5, pp. 776-796, 2007.

[31] J. J. Feng and F. Zhang, "Large Fluctuation research of hydromachine combined transition of Kabompo Hydropower Station," Guangdong Water Resources and Hydropower, vol. 11, 2014, [in Chinese].

[32] J. Yang, J. Yang, C. Wang, and H. Bao, "Simulation of pressure fluctuation of a pump turbine in load rejection," Shuili Fadian Xuebao/Journal of Hydroelectric Engineering, vol. 33, no. 4, pp. 286-294, 2014.

[33] J. S. Chang, Transient of hydraulic machine installations, Higher Education Press, Beijing, 1st edition, 2005, [in Chinese]. 


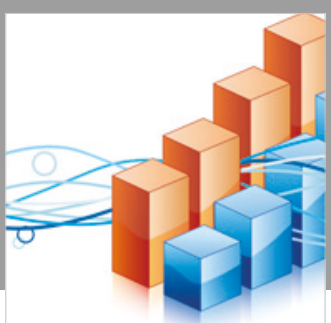

Advances in

Operations Research

\section{-n-m}
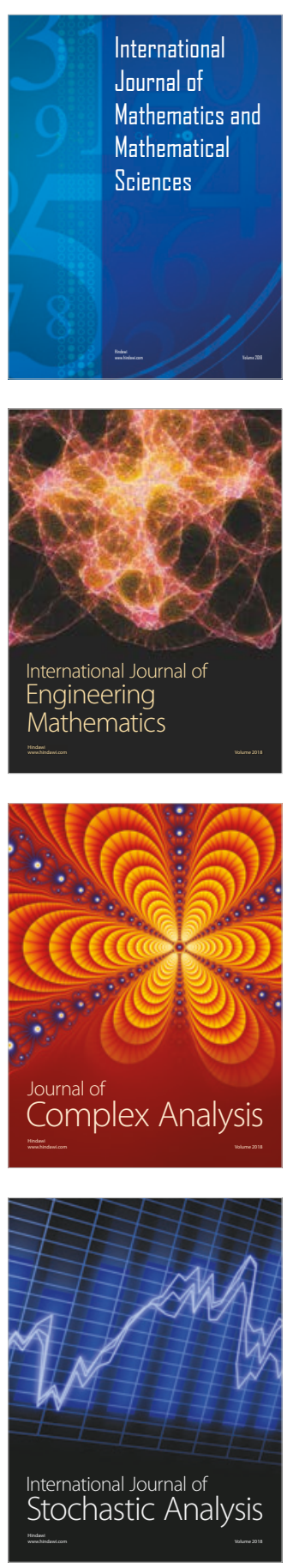
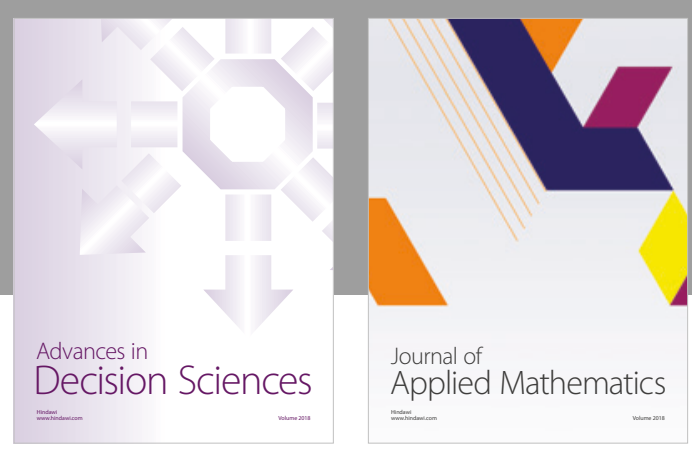

Journal of

Applied Mathematics
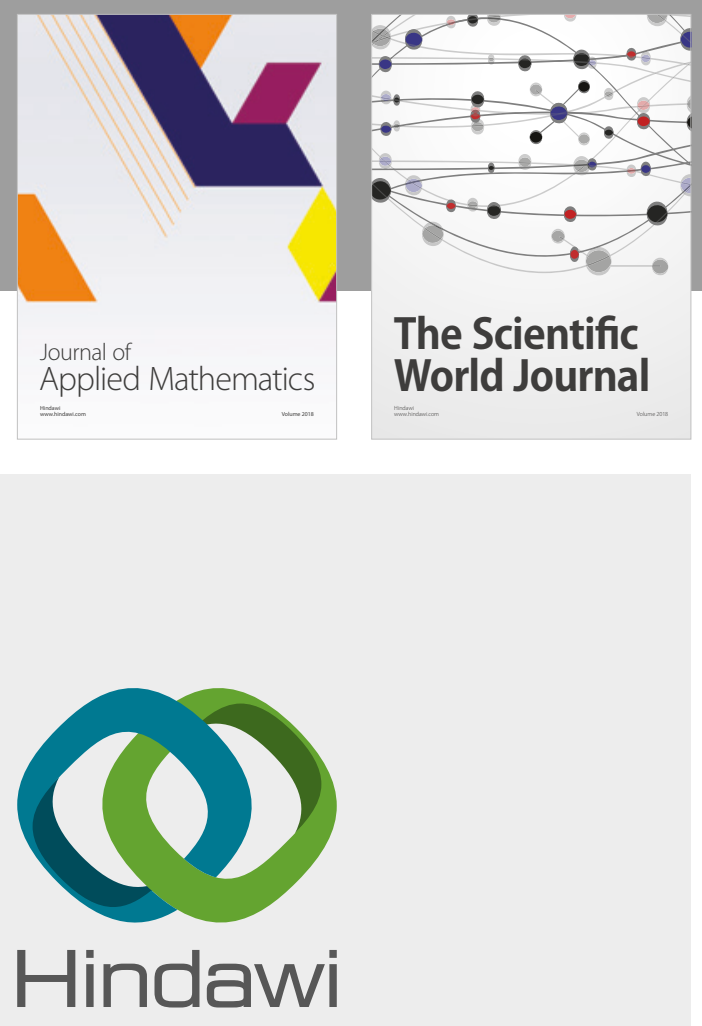

Submit your manuscripts at

www.hindawi.com

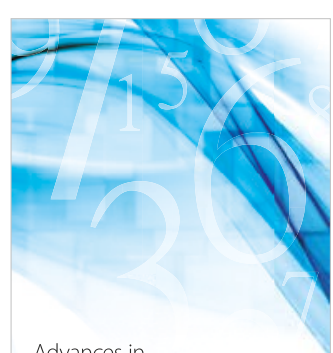

Advances in
Numerical Analysis
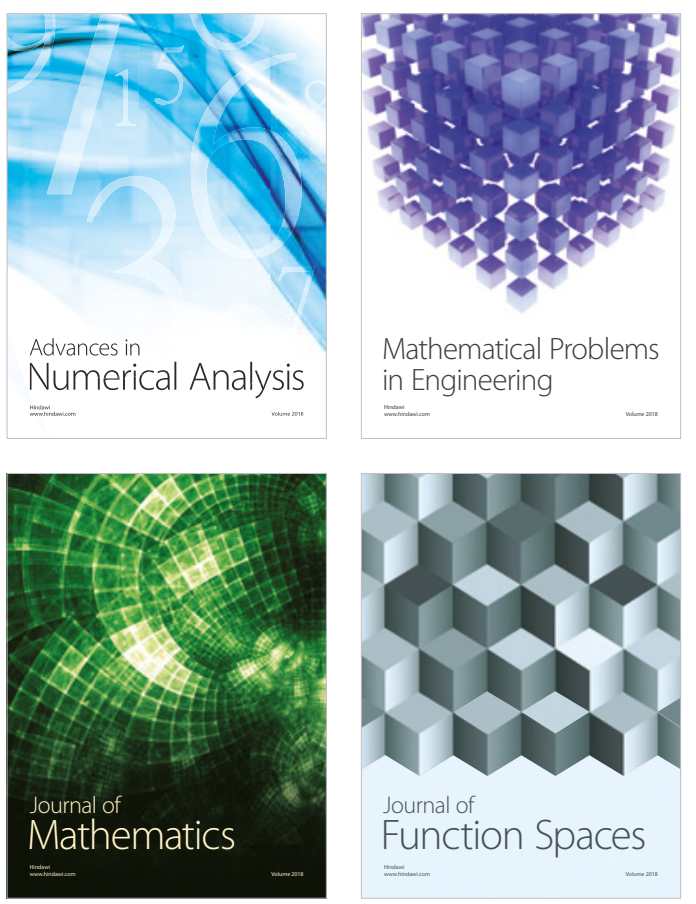

Mathematical Problems in Engineering

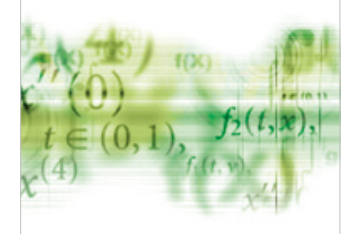

International Journal of

Differential Equations

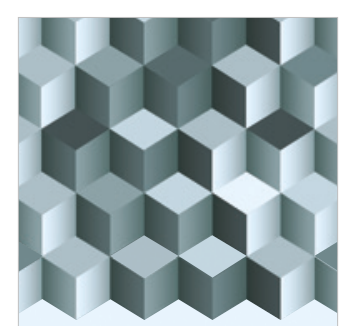

Journal of

Function Spaces
The Scientific

World Journal

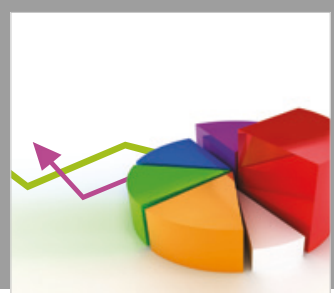

Journal of

Probability and Statistics
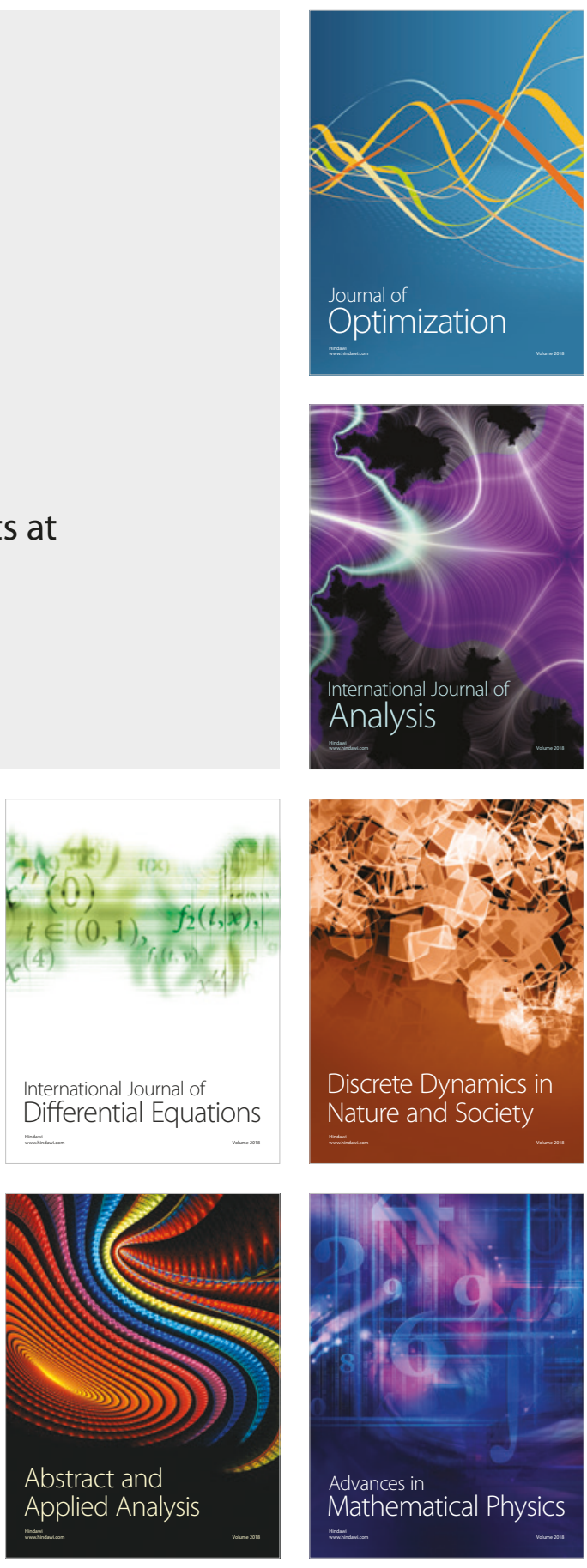